\title{
Long-term tricuspid valve function after Norwood operation
}

\author{
Maryam Elmi, BSc, ${ }^{\mathrm{b}}$ Edward J. Hickey, MD, ${ }^{\text {a }}$ William G. Williams, MD, ${ }^{\mathrm{a}}$ Glen Van Arsdell, MD, ${ }^{\mathrm{a}}$ \\ Christopher A. Caldarone, MD, ${ }^{a}$ and Brian W. McCrindle, $\mathrm{MD}^{\mathrm{b}}$
}

Objective: Long-term functional outcomes after Norwood palliation are likely to depend on tricuspid valve performance in the systemic role. We therefore aimed to characterize features associated with tricuspid valve intervention.

\begin{abstract}
Methods: All 219 children (1990-2007) who underwent Norwood stage 1 palliation resulting in a systemic right ventricle were investigated. In parametric competing risks analyses, primary end points included surgical tricuspid valve intervention (repair $=27$, replacement $=3$ ) and death $(\mathrm{N}=105)$. All 2705 echocardiogram reports were included in time-related analyses of outcome adjusted for repeated measures. Variable selection used bootstrapping.
\end{abstract}

Results: Approximately $25 \%$ of survivors underwent tricuspid valve repair at some point, especially in children with mitral atresia $(P=.04,53 \%$ reliability), longer myocardial ischemic time during $\operatorname{Norwood}(P=.02,50 \%)$, and moderate/severe tricuspid regurgitation immediately post-Norwood $(P=.006,86 \%)$. Risk of tricuspid valve intervention was mainly early, but a late risk emerged 10 to 15 years after Norwood. Tricuspid valve intervention was successful in restoring functional natural history to that of the remainder of the cohort. Tricuspid valve intervention did not compromise survival ( $82 \% \pm 2 \% 5$ years after tricuspid valve intervention), and right ventricular function was not worse in patients requiring tricuspid valve intervention. Repeat tricuspid valve interventions were undertaken in 6 patients (3 repairs, 3 replacements). At latest follow-up, the degree of tricuspid valve regurgitation was not different between those who did and did not receive intervention.

Conclusions: Tricuspid valve surgery is common after single ventricle palliation for hypoplastic left heart syndrome, necessary in up to $25 \%$ of survivors. Mitral atresia and lengthy myocardial ischemic times during Norwood surgery are prominent risks. Right ventricular function was preserved by tricuspid repair. However, the emerging late hazard for tricuspid valve intervention may have implications for long-term outcome and should be explored further. (J Thorac Cardiovasc Surg 2011;142:1341-7)

\section{Supplemental material is available online.}

Tricuspid valve (TV) performance in the systemic role is likely to have important implications for survival and functional status after univentricular palliation of hypoplastic left heart syndrome (HLHS). Important tricuspid regurgitation (TR) at the time of diagnosis is a known risk factor for early mortality after stage 1 Norwood palliation. ${ }^{1}$ However, important TR after palliative surgery subsequently develops in a proportion of infants with normal TV function preNorwood. ${ }^{2}$ Reasons for deteriorating TV function may

From the Division of Cardiovascular Surgery, ${ }^{\mathrm{a}}$ Department of Surgery, and Division of Cardiology, ${ }^{\mathrm{b}}$ Department of Pediatrics, University of Toronto, The Hospital for Sick Children, Toronto, Ontario, Canada.

Disclosures: Authors have nothing to disclose with regard to commercial support.

Received for publication Aug 16, 2009; revisions received Oct 18, 2010; accepted for publication Nov 25, 2010; available ahead of print June 27, 2011.

Address for reprints: Brian W. McCrindle, MD, The Hospital for Sick Children, 555

University Avenue, Toronto, Ontario, Canada M5G 1X8 (E-mail: brian. mccrindle@sickkids.ca).

0022-5223/\$36.00

Copyright (c) 2011 by The American Association for Thoracic Surgery

doi:10.1016/j.jtcvs.2010.11.065 include right ventricular (RV) volume loading, RV systolic and diastolic dysfunction, and myocardial ischemic injury during surgical palliation.

The natural and unnatural history of TV function over time have not been clearly delineated in infants with HLHS. We therefore undertook an investigation into our institutional experience with Norwood palliation in children with HLHS since 1990. Data acquisition included all known interventions and all echocardiograms known to have been performed. We aimed to (1) determine the prevalence and time-related risk of TV intervention after diagnosis, (2) characterize the patient-specific factors associated with greater risk of undergoing TV intervention, (3) model the time-related natural and unnatural history of valvular function, and (4) investigate outcomes after TV repair or replacement.

\section{MATERIALS AND METHODS \\ Study Design and Study Population}

We performed a single-center retrospective study of 219 consecutive infants at the Hospital for Sick Children who all underwent a stage 1 Norwood palliation for a diagnosis of aortic atresia or critical aortic stenosis between 1990 and 2007. Patients with all variants of HLHS were included unless they had atrioventricular or ventriculoarterial discordant 


$$
\begin{aligned}
& \text { Abbreviations and Acronyms } \\
& \begin{aligned}
\text { HLHS } & =\text { hypoplastic left heart syndrome } \\
\text { RV } & =\text { right ventricular } \\
\text { TR } & =\text { tricuspid regurgitation } \\
\text { TV } & =\text { tricuspid valve }
\end{aligned}
\end{aligned}
$$

connections or an interrupted aortic arch. Institutional ethics board approval was obtained, and a waiver of consent was granted because of the study's retrospective nature and because patients were not contacted.

\section{Follow-up and Data Acquisition}

Follow-up was undertaken in 2007 via chart review to a median of 5.1 years for survivors (range, $0-15.9$ years), providing 749 patient-years of data. All available reports pertaining to surgical interventions, cardiac catheterizations, and autopsies were obtained. To model time-related progression of valvular function (repeated-measures analysis), reports of all echocardiograms were obtained $(\mathrm{N}=2705)$ throughout the follow-up period. Variables pertaining to demographics, baseline morphology, operative features at the time of stage 1 Norwood palliation, and echocardiographic dimensions and functional indices were abstracted from reports for subsequent risk-hazard and repeated-measures analyses.

\section{Analysis of Time-Related Events}

Separate parametric models of time-related events from the time of diagnosis were generated using multiphase hazard domain techniques. ${ }^{3}$ For end points other than death, competing risks methodology was used to account for children who died and were therefore no longer at risk of the event occurring. Patients were therefore censored at the last point of follow-up or the time of an alternative mutually exclusive end state occurring (competing risk). Selected patient-specific characteristics (Table E1) were abstracted from reports and used for multivariable risk-hazard analysis using these parametric models. Dimensional variables were standardized and expressed as $z$ scores on the basis of published normative data if avail$a^{2} e^{4}$ or otherwise indexed to body surface area. All continuous variables were examined by decile analysis to determine possible transformations to improve linear calibration. Multivariable analysis was undertaken by forward stepwise regression. Missing values were imputed with the mean for that variable. Variables with excessive $(>75 \%)$ missing values or associated with fewer than 5 events were suppressed during multivariable analysis to reduce the risk of overdetermination. Final selection of variables was guided by bootstrap bagging ${ }^{5}(n=1000$, threshold for inclusion $P<.1)$ to test the robustness of risk factors; those appearing in $50 \%$ or more of models or clusters were considered reliable for inclusion.

\section{Analysis of Repeated Measures}

Time-related progression of TV regurgitation and RV function were explored by examining serial echocardiographic measurements in linear regression models to produce generalized estimating equations adjusted for repeated measures through autoregressive covariance structure. Patients were censored at the point of intervention. Variable selection was undertaken by backward elimination.

\section{Modulated Renewal Methodology}

To compare outcomes of successive interventions, modulated renewal process methodology was used. ${ }^{6,7}$ Patients experiencing a first event are restarted at a new time zero and tracked to the next event, and so forth, for each successive event. The cumulative hazard for all TV interventions $(\mathrm{N}=30)$ on the 219 patients was therefore modeled and stratified by the sequence of interventions to the TV. Stratified plots were generated by creating survival curves for each individual patient. Curves within stratification groups were then aggregated, and the mean was then compared with Kaplan-Meier estimates.

Data are described as frequencies, medians with ranges, or means with standard deviations. Actual time-related outcomes were calculated using Kaplan-Meier principles. Data were entered and analyzed using SAS statistical software, version 9 (SAS Institute, Inc, Cary, NC).

\section{RESULTS}

All 219 infants in this investigation were diagnosed with aortic atresia or critical aortic stenosis and underwent Norwood palliation as part of a univentricular strategy. Of the total cohort, $30 \mathrm{TV}$ surgical interventions were performed in 24 children. All 24 primary TV interventions were valvuloplasties. The $6 \mathrm{TV}$ reinterventions were revalvuloplasties $(\mathrm{N}=3)$ or mechanical valve replacements $(\mathrm{N}=3)$.

Patient-specific features are shown in Table E1. In children who underwent TV intervention, the prevalence of pre-Norwood aortic coarctation was significantly lower $(P=.001)$, mitral annular $z$ scores were smaller $(P=.01)$, and distribution of birth weights was lower $(P=.004)$. Otherwise, features at the time of diagnosis and during Norwood stage 1 were similar between those who did and did not undergo TV surgery.

\section{Time-Related Risk of Undergoing Tricuspid Valve Intervention}

The hazard of undergoing TV procedures comprised 2 main periods of risk. An early hazard phase predominated for the initial 5 years after diagnosis and accounted for the large majority of interventions $(>90 \%)$. A late period of risk appeared to emerge beyond 5 years after diagnosis (Figure 1). However, an important number of children died early during follow-up and therefore were no longer at risk of undergoing TV intervention. Consequently, competing risks methodology more accurately describes the outcomes for the cohort: Ten years after diagnosis, $12 \%$ $\pm 3 \%$ had undergone TV intervention, $48 \% \pm 4 \%$ had died without TV intervention, and $41 \% \pm 3 \%$ remained alive and free from TV intervention (Figure 2, $A$ ). Therefore $23 \%$ of all survivors had undergone TV intervention within the first 10 years after diagnosis.

\section{Risk Factors for Tricuspid Valve Intervention}

Incremental risk factors (at the time of diagnosis) for TV intervention included presence of mitral atresia and longer myocardial ischemia during Norwood operation (Table 1). Of note, indexed TV annular dimensions, TR grade at the time of diagnosis, and other TV morphologic features were not associated with time-related risk of TV intervention in this cohort. In addition, shunt type (Sano vs modified Blalock-Taussig), shunt size, and age at volume unloading (cavopulmonary shunt) were not associated with timerelated need for TV intervention. 

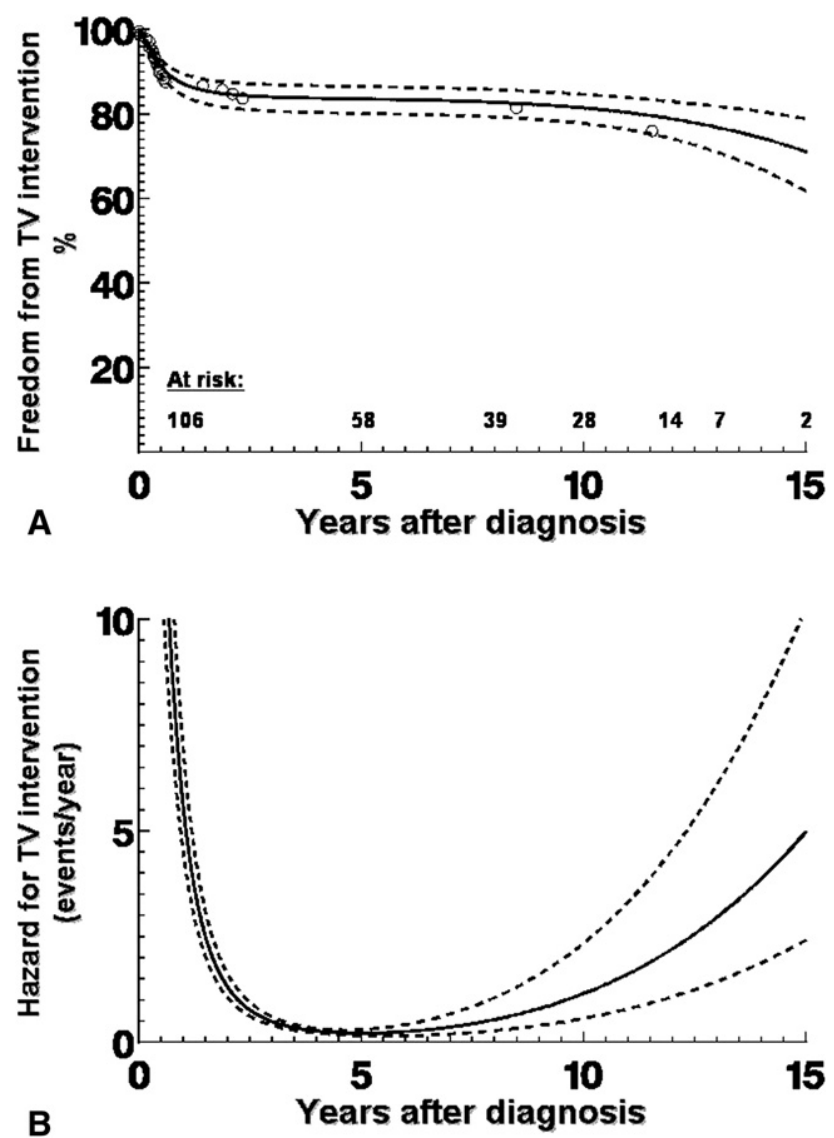

FIGURE 1. A, Freedom from TV intervention in children with HLHS managed with the Norwood operation $(\mathrm{N}=219)$. TV intervention was undertaken in 24 patients (of whom 6 underwent additional reintervention to the TV). B, Hazard function for TV intervention. The hazard for TV intervention comprised 2 main periods of risk. The early hazard phase predominated within the first 5 years, and $75 \%$ of all reinterventions were within 1 year of diagnosis. A second later phase appeared to emerge beyond 5 years after diagnosis. During the study period, $92 \%$ of TV interventions were attributable to the early hazard component, and $8 \%$ were attributable to the late hazard component. Circles represent nonparametric estimates at events; solid lines represent parametric determinants of continuous point estimates; dashed lines and bars enclose $70 \%$ confidence intervals. TV, Tricuspid valve.

Incremental risk factors for the competing risk of death without TV intervention included smaller birth weight, earlier operative era, absence of aortic coarctation, and smaller indexed branch pulmonary arteries. At the time of Norwood operation, longer exposure to deep hypothermic circulatory arrest and younger age were additional features contributing to greater risk of death (Table 1).

For any given child, a constellation of aforementioned competing risk factors determines the likelihood of reaching a given end state at a certain point in time. For instance, in a child with a birth weight of $4 \mathrm{~kg}$ with mitral atresia who undergoes the Norwood operation on day 7 of life with 100 minutes of myocardial ischemia and 15 minutes of deep
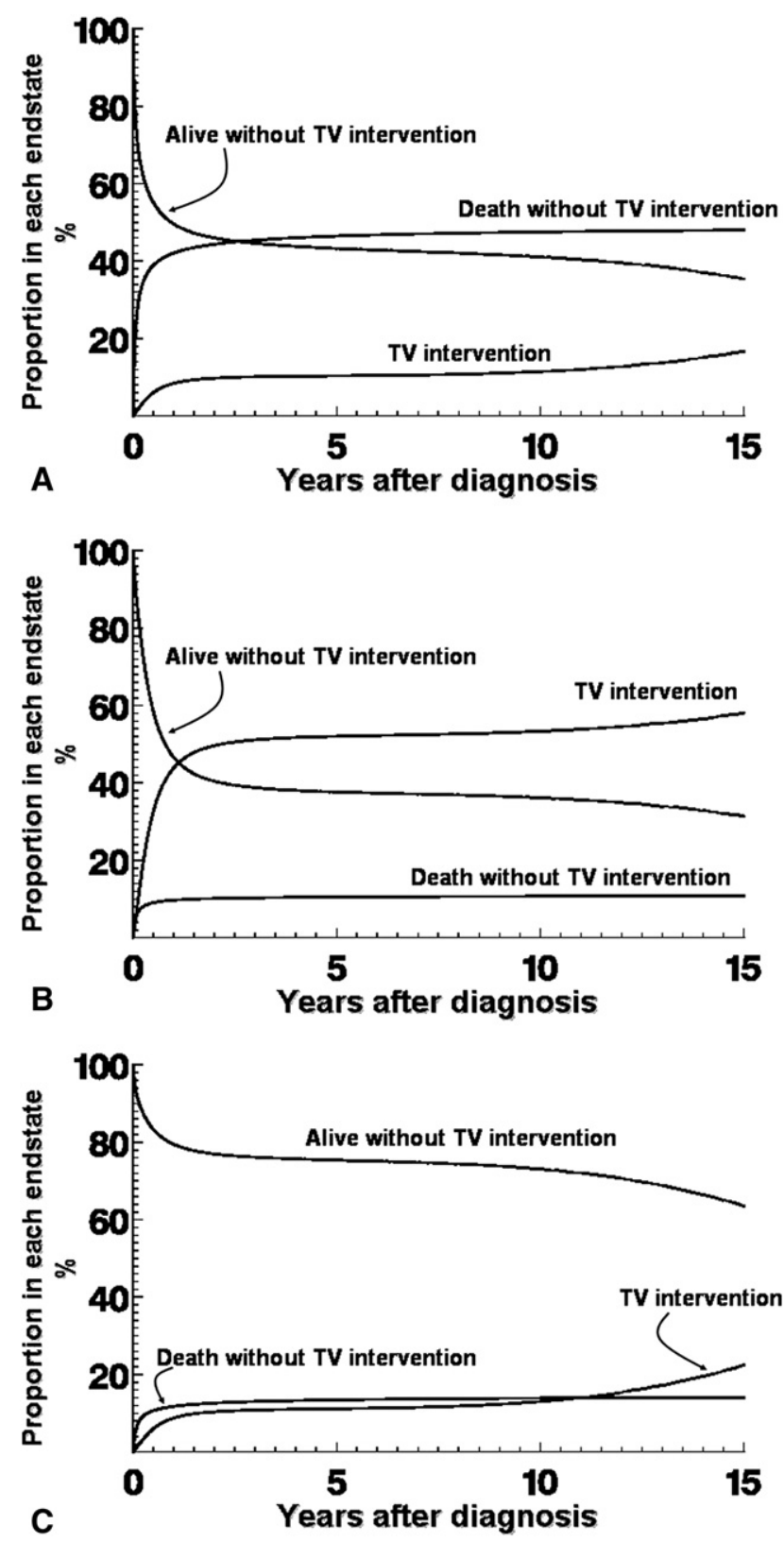

FIGURE 2. A, Competing risks of death and TV intervention. After diagnosis, all children are subject to the mutually exclusive competing risks of (1) undergoing TV intervention ( $\mathrm{N}=24)$, (2) death without TV intervention $(\mathrm{N}=100)$, or (3) remaining alive without reintervention $(\mathrm{N}=95)$. Ten years after the index procedure, $12 \% \pm 3 \%$ had undergone TV intervention, $48 \% \pm 4 \%$ had died without TV intervention, and $41 \% \pm 3 \%$ remained alive and free from TV intervention. Therefore, approximately one quarter of survivors had at some point undergone an intervention to the TV. The competing risks plot has then been stratified according to (B) unfavorable features (4-kg infant with mitral atresia undergoing repair with myocardial ischemic time of 100 minutes and deep hypothermic circulatory arrest time of 15 minutes) or (C) favorable features (4-kg infant with patent mitral valve undergoing repair with only 60 minutes of myocardial ischemia and 15 minutes of deep hypothermic circulatory arrest). Lines represent parametric determination of the continuous point estimates of the percentage of patients within each category. $T V$, Tricuspid valve. 
TABLE 1. Incremental risk factors for the competing risks of tricuspid valve intervention or death without tricuspid valve intervention

\begin{tabular}{lccc}
\multicolumn{1}{c}{ Variable } & PE & $\begin{array}{c}\boldsymbol{P} \\
\text { value }\end{array}$ & $\begin{array}{c}\% \\
\text { reliability }\end{array}$ \\
\hline $\begin{array}{l}\text { Risk factors for TV intervention } \\
\text { Morphologic and demographic risks }\end{array}$ & & & \\
$\quad$ Mitral atresia & +0.92 & .04 & 53 \\
Procedural factors at time of Norwood & & & \\
$\quad$ Longer crossclamp duration* & +0.023 & .02 & 50 \\
Immediate post-Norwood factors & & & \\
$\quad$ Moderate/severe TR in ICU & +1.32 & .006 & 86 \\
Risk factors for death without TV & & & \\
intervention & & & \\
Morphologic and demographic risks & & & \\
$\quad$ Smaller birth weight & +0.83 & $<.0001$ & 57 \\
$\quad$ Earlier operative year & +0.14 & $<.0001$ & 99 \\
$\quad$ Absence of aortic coarctation & +0.40 & .05 & 62 \\
$\quad$ Smaller branch pulmonary arteries & +0.084 & .01 & 50 \\
Procedural factors at time of Norwood & & & \\
$\quad$ Smaller birth weight & +0.84 & $<.0001$ & 99 \\
$\quad$ Longer DHCA duration & +0.025 & .0002 & 90 \\
$\quad$ Earlier operative year & +0.056 & .04 & 95 \\
$\quad$ Younger age at operation & +0.28 & .02 & 51 \\
\hline$D H C A$ Dep
\end{tabular}

$D H C A$, Deep hypothermic circulatory arrest; $I C U$, intensive care unit; $P E$, parameter estimate. Reliability is the bootstrap reliability of the variable's $P$ value. *Excluding those in whom TV repair was concomitant with Norwood stage 1.

hypothermic circulatory arrest, the subsequent risk of requiring TV intervention is high: More than half of all survivors will have undergone TV intervention within a few years of diagnosis (Figure 2, B). By contrast, a constellation of features, including birth weight of $4 \mathrm{~kg}$, mitral valve patency, and shorter myocardial ischemic times, confer a low risk of subsequent TV intervention, less than $10 \%$ within 10 years of diagnosis, in addition to a low risk of death (Figure 2,C).

All patients received on-table transesophageal or epicardial echocardiography at the time of the Norwood operation. Our strategy throughout the era spanned by this study has been to address moderate or severe TR present at the time of on-table echocardiography. Nevertheless, 21 patients $(10 \%)$ had TR graded by transthoracic echocardiography on the first formal postoperative investigation in intensive care. In 20 of 21 patients (95\%), this hemodynamically significant TR was a new occurrence, having been mild or less pre-Norwood. Moderate/severe TR immediately postNorwood was itself a strong risk factor for time-related need for subsequent TV intervention (parameter estimate $+1.32, P<.006,86 \%$ bootstrap resamples).

\section{Timing and Nature of Tricuspid Valve Procedures}

All TV interventions were for a primary indication of regurgitation, with or without some degree of RV dysfunction (Table 2). At operation, the anatomic and functional findings were highly variable. Of all $30 \mathrm{TV}$ procedures ( primary $=24$; secondary $=6$ ), 19 were undertaken
TABLE 2. Surgical details and findings at operation in children who underwent tricuspid valve surgical intervention

\begin{tabular}{|c|c|c|c|}
\hline \multirow[b]{2}{*}{ Variable } & \multicolumn{3}{|c|}{ First TV repair $N=\mathbf{2 4}$} \\
\hline & $\begin{array}{c}\text { Missing } \\
\text { variables }\end{array}$ & No. & $\begin{array}{l}\% \text { or } \\
\text { range }\end{array}$ \\
\hline Repair & 0 & 24 & - \\
\hline Replacement & 0 & 0 & - \\
\hline \multicolumn{4}{|l|}{ Indications } \\
\hline Moderate regurgitation & 1 & 14 & 61 \\
\hline Severe regurgitation & 1 & 5 & 22 \\
\hline Leaflet prolapse & 1 & 3 & 13 \\
\hline Heart failure & 1 & 2 & 9 \\
\hline Right ventricular dysfunction & 1 & 14 & 61 \\
\hline \multicolumn{4}{|l|}{ Area of incompetency on inspection } \\
\hline Unspecified & 13 & 4 & 36 \\
\hline Posterior leaflet & 13 & 2 & 18 \\
\hline Anterior leaflet & 13 & 3 & 27 \\
\hline Septal leaflet & 13 & 1 & 9 \\
\hline Septal-anterior commissure & 13 & 1 & 9 \\
\hline \multicolumn{4}{|l|}{ Morphologic abnormalities on inspection } \\
\hline Cleft (anterior leaflet) & 13 & 4 & 36 \\
\hline Septation (septal leaflet) & 13 & 1 & 9 \\
\hline Triangular leaflet & 13 & 2 & 18 \\
\hline Accessory leaflet & 13 & 1 & 9 \\
\hline \multicolumn{4}{|l|}{ Surgical details } \\
\hline Concomitant: Norwood stage 1 & 0 & 2 & 8 \\
\hline Concomitant: cavopulmonary shunt & 0 & 12 & 50 \\
\hline Concomitant: Fontan completion & 0 & 3 & 13 \\
\hline $\begin{array}{l}\text { Concomitant: pulmonary artery } \\
\text { augmentation }\end{array}$ & 0 & 2 & 8 \\
\hline Bypass time (min), median & 6 & 113 & $50-205$ \\
\hline Aortic crossclamp time (min), median & 7 & 45 & $16-142$ \\
\hline PA commissure closure & 10 & 3 & 21 \\
\hline PS commissure closure & 10 & 4 & 29 \\
\hline AS commissure closure & 10 & 8 & 57 \\
\hline Unspecified commissure closure & 10 & 3 & 21 \\
\hline Annuloplasty & 10 & 5 & 36 \\
\hline Cleft closure & 10 & 2 & 14 \\
\hline Leaflet augmentation & 10 & 1 & 7 \\
\hline
\end{tabular}

$A S$, Anterior-septal; $P A$, posterior-anterior; $P S$, posterior-septal. Frequencies are expressed as a proportion of nonmissing values.

concomitant with Norwood stage 1, bidirectional cavopulmonary shunt, or Fontan procedure (Table 2). Therefore, for 11 patients in this series, TV intervention was the primary procedure outside the typical univentricular surgical paradigm. The need for intervention specifically for TV abnormalities would be of particular interest to families and physicians alike (Figure E1). However, the only reliable risk factor for TV as an isolated procedure was the presence of mitral atresia $(P=.0007)$.

\section{Functional Results of Tricuspid Valve Intervention}

Children who underwent TV interventions were distinguished preoperatively by higher grades of TR. Moreover, the severity of their TR had gradually increased over time 
$(P<.0001)$. Tricuspid valvuloplasty then resulted in a significant immediate improvement in echocardiographic grade of functional regurgitation $(P=.0003$, Figures $3, A$, and E2, A). Thereafter, the severity of their TR remained stable, or even tended to decline over the course of follow-up $(P=.08$, Figure $3, A)$.
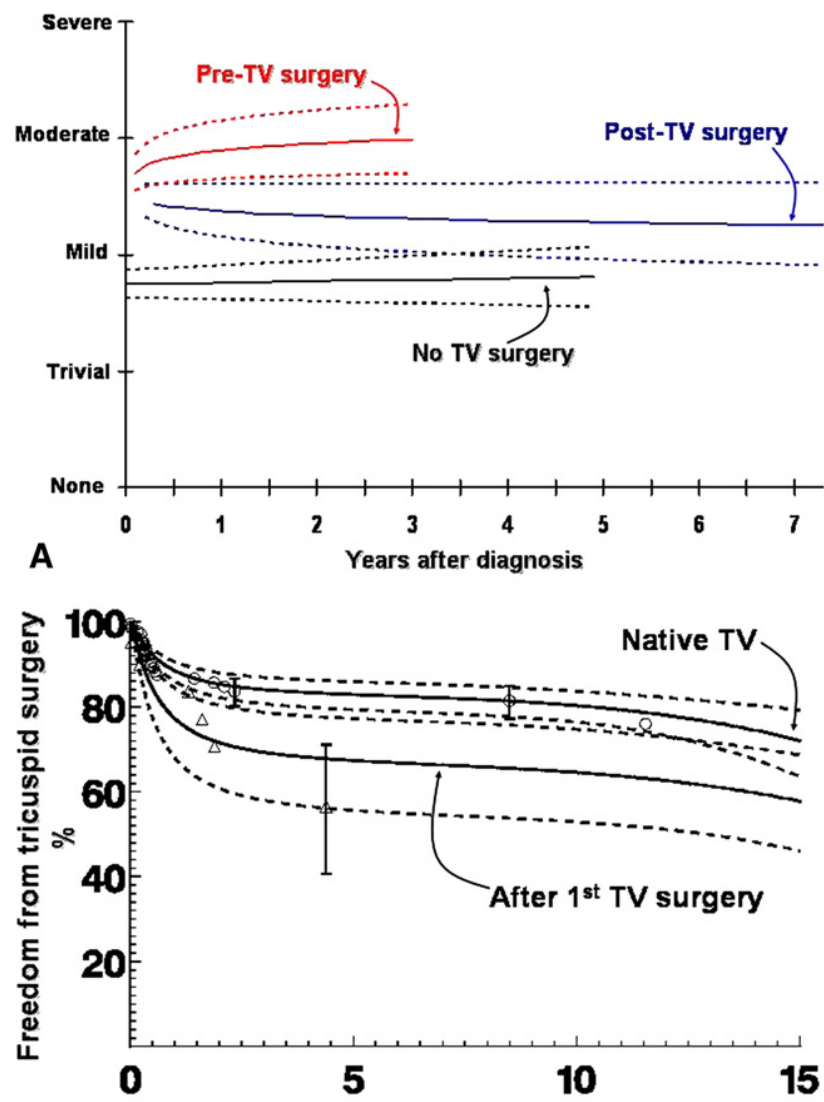

B Years after diagnosis or previous tricuspid surgery

FIGURE 3. A, Parametric regression estimates of the time-related change in echocardiographic grade of TR. Patients who underwent TV intervention were characterized by having a higher preoperative grade of regurgitation that worsened significantly over time (parameter estimate +0.19 , $P<.0001)$. However, after intervention, the grade of regurgitation was improved and showed no significant time-related deterioration in regurgitation thereafter. In fact, grade of regurgitation tended to improve over time after intervention $(P=.08)$, thereby more closely approximating those patients who did not undergo TV intervention. Time has been entered as the log-transformation to improve model fit. Number of nonmissing values for analysis: patients not receiving $\mathrm{TV}$ intervention, $\mathrm{N}=1731$; preoperative TV intervention, $\mathrm{N}=204$; postoperative TV intervention, $\mathrm{N}=190$. B, Modulated renewal analysis of freedom from TV intervention, stratified according to baseline versus after an initial TV intervention. Freedom from TV intervention tended to be worse after already having undergone a prior tricuspid intervention in risk-unadjusted models $(P=.10)$. However, in risk-adjusted models freedom from subsequent intervention was not different $(P=.57)$. Lines represent parametric determination of continuous point estimates, symbols represent Kaplan-Meier estimates at each event (reintervention); bars enclose $70 \%$ confidence intervals. TV, Tricuspid valve.
After univentricular palliation for HLHS, preservation of $\mathrm{RV}$ function in the systemic role is of central importance. Immediately after surgical intervention to the TV, RV performance was no different or even slightly worse (Figure E2, B); however, long-term RV performance in children who required TV intervention was identical to those who did not require intervention, with no obvious late deterioration (Figure E2, C).

\section{Tricuspid Valve Reintervention}

The time-related risk of reintervention to the TV was examined using modulated renewal methodology. Modulated renewal analyses explore whether undergoing a first TV intervention places a patient at higher risk of undergoing a second TV intervention. Reinterventions were necessary in 6 children (repair $=3$; replacement $=3$ ). Although longevity of the TV repair tends to be inferior to that of native valves in risk-unadjusted models $(P=.10$, Figure $3, B)$, this difference is not significant $(P=.57)$ in risk-adjusted models. Furthermore, on univariate analysis, no aspects specific to the initial TV intervention were associated with increased risk of reintervention. Finally, overall survival in children who underwent TV intervention was excellent: $82 \% \pm$ $6 \%$ at 5 years (from the point of intervention to the TV).

\section{DISCUSSION}

Our data demonstrate that important TV dysfunction is common in infants born with HLHS managed via univentricular palliation: Approximately one quarter of all survivors will have undergone surgical TV procedures within 10 years. In fact, new-onset TR may be seen in as many as $10 \%$ of children immediately post-Norwood, and this finding itself indicates high risk of subsequent need for tricuspid intervention. Most TV interventions are undertaken in the early years of childhood. However, several children have required TV repair late after Fontan completion; the possibility of an emerging late hazard for TV dysfunction carries important functional health implications for children with Fontan physiology.

Among surgically managed patients with HLHS, attrition between stages ("interstage death") and death later in childhood are both significant concerns. ${ }^{8-10}$ Development of significant TR remains an obstacle in improving survival after the Norwood procedure, ${ }^{11-14}$ and likely compromised functional health after the Fontan procedure. Thus, prevention of TV deterioration seems pivotal to improving long-term outcomes for patients with HLHS. By identifying children at risk of developing severe TV dysfunction, perhaps there are preemptive strategies (pharmacologic or interventional) that can be implemented early to optimize tricuspid function and decrease interstage risk. Our study identified factors predictive for undergoing a later TV intervention (Table 1). Perhaps patients with these presenting features should have a lower threshold 
for TV repair at the time of Norwood operation, in addition to being more closely followed for tricuspid dysfunction postoperatively. Pharmacologic strategies to limit TR (eg, afterload reduction) might be considered early for highrisk patients.

The early period of risk for TV intervention during infancy is in part determined by the timing of the 3 staged procedures in the Norwood-Fontan pathway. It is intuitively sensible to undertake concomitant $\mathrm{TV}$ repair at the time of a necessary surgical stage. As such, in our series, the majority (19/30) of TV repairs were undertaken as a concomitant staged operation. Incorporating the TV repair as part of an alternate procedure does not render it inconsequential but instead indicates that the child already exhibits significant functional handicaps with regard to a (right) univentricular circulation, even early on. How or whether this will affect survival and functional performance beyond the follow-up of this investigation is of considerable importance. Although no other institution has investigated the time-related risk for TV intervention, some investigators have reported mean ages for TV repairs consistent with our proposed early hazard phase. ${ }^{15,16}$ This implies that particular attention must be given to the TV early in the surgical paradigm, perhaps in the peri-Norwood period as a preventative measure.

More than one third of TV interventions (11/30) were undertaken outside the typical univentricular surgical paradigm. This subset of children are especially important because they presumably reflect TV dysfunction that mandated isolated tricuspid intervention on the grounds of severity or late onset. It is interesting that the most important and reliable determinant of TV intervention outside the usual univentricular operative paradigm was the presence of mitral atresia. In mitral atresia (similar to most cases of aortic atresia), left ventricular flow is completely absent. All systemic cardiac output must necessarily be generated via the RV (by contrast, in univentricular repair of critical aortic stenosis, a small proportion of systemic cardiac output will be via the left heart). When left ventricular flow is zero, presumably the right cardiac structures are therefore operating under maximum hemodynamic stress.

A small, but important, number of children underwent TV repair well beyond completion of Fontan physiology. The principal concern is that tricuspid dysfunction may be a consequence of a failing systemic RV, perhaps due to annular dilatation. Thereafter, TR will further exacerbate ventricular failure in a detrimental positive feedback loop. Tricuspid repair is frequently necessary in those requiring intervention for RV failure after atrial switch repair of transposition of the great arteries. ${ }^{17}$ Likewise, in patients dying of RV failure late after the Senning or Mustard operation, severe TR is invariably present. ${ }^{18} \mathrm{TV}$ repair or replacement in the context of severe RV dysfunction often does not lead to ventricular recovery. ${ }^{18}$ The importance of preserving late $\mathrm{TV}$ and RV performance after univentricular repair of HLHS is probably equally real.

Atresia of the mitral valve seems to be strongly associated with subsequent development of important TV dysfunction requiring intervention. Perhaps more important, mitral atresia was especially associated with TV repair or replacement being undertaken as isolated procedures, outside of the typical univentricular surgical paradigm. How atresia of left-sided structures influences TV performance is not obvious. Echocardiographic studies suggest that forces transmitted from the contracting left ventricle may influence TV annular functional morphology. ${ }^{2}$

Longer myocardial ischemic time during the Norwood operation was also identified as a risk factor for TV intervention. Correct atrioventricular valve function is known to be dependent on ventricular morphology and coordinated contraction of the wall and papillary muscles. Subendocardial ischemic injury may lead to papillary muscle dysfunction or late remodeling of RV geometry. Alternatively, it is possible that longer myocardial ischemic time is a surrogate for more complex cardiac morphology and an indirect risk factor for valvular regurgitation.

TV features and initial grade of TR at the time of diagnosis were not particularly robust predictors of the need for subsequent tricuspid repair. It is likely these are important, but they may have been overshadowed by other more reliable risks. Detailed echocardiographic indices of tricuspid morphology (annular area, annular area changes, saddle shape, and segmental diameter changes) are known to correlate with regurgitation. ${ }^{2}$ It is therefore likely that such features would also be predictive in patients with HLHS.

Numerous reports have previously examined risk factors for death after univentricular repair of HLHS. The risk factors we describe are consistent with these earlier reports, including lower birth weight, earlier operative era, longer deep hypothermic circulatory arrest time, and compromised pulmonary flow. ${ }^{19-21}$

It is reassuring that $\mathrm{TV}$ interventions were effective at producing a sustained and significantly reduced grade of regurgitation. Furthermore, RV function in those patients who required tricuspid repair paralleled those who did not. Presumably, this is because TR was addressed before any functionally detrimental changes to the RV occurred. The Michigan group ${ }^{22}$ suggested that success of TV repair is contingent on RV function; the presence of significant RV dysfunction instead results in continued deterioration of TV performance even after intervention. Overall, there is consensus in the literature that TV repair is a useful and effective adjunct to staged surgical palliation in HLHS. ${ }^{15,16,22-24}$ The favorable survival after TV intervention, both in our series and others, ${ }^{15,16}$ seems to corroborate this view. 


\section{Limitations}

One important limitation of the study is that TV repairs in infancy are frequently incorporated in the staged operations. Therefore, intervals to TV intervention are clustered around the time of cavopulmonary shunt and Fontan operations (and are unlikely to be precise surrogates for the interval to onset of important TR). However, we do not think this influences the conclusions drawn from our investigation. The principal purpose of using multiphase time-related techniques was to scrutinize for a late component. The small number of late TV interventions present in our series is interesting and has potential importance. However, this finding is hampered by the restraints of sample size and duration of follow-up. Larger, multi-institutional research databases are likely to be especially useful to more accurately examine the late functional performance of the systemic RV in HLHS.

\section{CONCLUSIONS}

Important TV dysfunction is common late after univentricular repair of HLHS. Approximately one quarter of survivors will have undergone a TV intervention within 10 years. A late risk may be emerging and needs to be explored further because it would have important functional implications. Risk of requiring TV repair seems to be particularly associated with atretic left-sided morphology: aortic or mitral atresia. Certain features at the time of diagnosis may therefore be useful in predicting long-term durability of TV performance. However, when required, TV interventions seem durable and associated with favorable survival.

\section{References}

1. Hickey EJ, Caldarone CA, Blackstone EH, Lofland GK, Yeh T Jr, Pizarro C, et al. Critical left ventricular outflow tract obstruction: the disproportionate impact of biventricular repair in borderline cases. J Thorac Cardiovasc Surg. 2007;134: 1429-37.

2. Nii M, Guerra V, Roman KS, Macgowan CK, Smallhorn JF. Three-dimensional tricuspid annular function provides insight into the mechanisms of tricuspid valve regurgitation in classic hypoplastic left heart syndrome. JAm Soc Echocardiogr. 2006;19:391-402

3. Blackstone EH, Naftel DC, Turner MEJ. The decomposition of time-varying hazard into phases, each incorporating a separate stream of concomitant information. J Am Stat Assoc. 1986;81:615-24.

4. Daubeney PE, Blackstone EH, Weintraub RG, Slavik Z, Scanlon J, Webber SA. Relationship of the dimension of cardiac structures to body size: an echocardiographic study in normal infants and children. Cardiol Young. 1999;9:402-10.

5. Breiman L. Bagging predictors. Machine Learning. 1996;24:123-40.
6. Kouchoukos NT, Blackstone EH, Doty DB, Hanley FL, Karp RB. Cardiac Surgery. 3rd ed., Vol. 1. Philadelphia, PA: Churchill Livingstone; 2003.

7. Kalbfleisch JD, Prentice RL. The Statistical Analysis of Failure Time Data. New York: Wiley; 1983.

8. Azakie T, Merklinger SL, McCrindle BW, Van Arsdell GS, Lee KJ, Benson LN, et al. Evolving strategies and improving outcomes of the modified Norwood procedure: a 10-year single-institution experience. Ann Thorac Surg. 2001;72: 1349-53.

9. Ishino K, Stumper O, De Giovanni JJ, Silove ED, Wright JG, Sethia B, et al. The modified Norwood procedure for hypoplastic left heart syndrome: early to intermediate results of 120 patients with particular reference to aortic arch repair. $J$ Thorac Cardiovasc Surg. 1999;117:920-30.

10. Tweddell JS, Hoffman GM, Mussatto KA, Fedderly RT, Berger S, Jaquiss RD, et al. Improved survival of patients undergoing palliation of hypoplastic left heart syndrome: lessons learned from 115 consecutive patients. Circulation. 2002;106: I82-9.

11. Barber G, Helton JG, Aglira BA, Chin AJ, Murphy JD, Pigott JD, et al. The significance of tricuspid regurgitation in hypoplastic left-heart syndrome. Am Heart J. 1988;116:1563-7.

12. Bove EL, Lloyd TR. Staged reconstruction for hypoplastic left heart syndrome. Contemporary results. Ann Surg. 1996;224:387-95.

13. Chang AC, Farrell PE Jr, Murdison KA, Baffa JM, Barber G, Norwood WI, et al. Hypoplastic left heart syndrome: hemodynamic and angiographic assessment after initial reconstructive surgery and relevance to modified Fontan procedure. $J$ Am Coll Cardiol. 1991;17:1143-9.

14. Mosca RS, Bove EL. Tricuspid valvuloplasty in hypoplastic left heart syndrome. Semin Thorac Cardiovasc Surg Pediatr Card Surg Annu. 1999;2:21-34.

15. Kanter KR, Forbess JM, Fyfe DA, Mahle WT, Kirshbom PM. De Vega tricuspid annuloplasty for systemic tricuspid regurgitation in children with univentricular physiology. J Heart Valve Dis. 2004;13:86-90.

16. Ohye RG, Gomez CA, Goldberg CS, Graves HL, Devaney EJ, Bove EL. Tricuspid valve repair in hypoplastic left heart syndrome. J Thorac Cardiovasc Surg. 2004; 127:465-72.

17. Horer J, Karl E, Theodoratou G, Schreiber C, Cleuziou J, Prodan Z, et al. Incidence and results of reoperations following the Senning operation: 27 years of follow-up in 314 patients at a single center. Eur J Cardiothorac Surg. 2008;33: 1061-8.

18. Carrel T, Pfammatter JP. Complete transposition of the great arteries: surgical concepts for patients with systemic right ventricular failure following intraatrial repair. Thorac Cardiovasc Surg. 2000;48:224-7.

19. Ashburn DA, McCrindle BW, Tchervenkov CI, Jacobs ML, Lofland GK, Bove EL et al. Outcomes after the Norwood operation in neonates with critical aortic stenosis or aortic valve atresia. J Thorac Cardiovasc Surg. 2003;125:1070-82.

20. Gaynor JW, Mahle WT, Cohen MI, Ittenbach RF, DeCampli WM, Steven JM, et al. Risk factors for mortality after the Norwood procedure. Eur J Cardiothorac Surg. 2002;22:82-9.

21. Knott-Craig CJ, Julsrud PR, Schaff HV, Puga FJ, Danielson GK. Pulmonary artery size and clinical outcome after the modified Fontan operation. Ann Thorac Surg. 1993;55:646-51.

22. Bove EL, Ohye RG, Devaney EJ, Hirsch J. Tricuspid valve repair for hypoplastic left heart syndrome and the failing right ventricle. Semin Thorac Cardiovasc Surg Pediatr Card Surg Annu. 2007;101-4.

23. Ota N, Ikai A, Hirose K, Sakamoto K. Retrospective analysis of stage I Norwood procedures with tricuspid valve insufficiency in the past 5 years. Interact Cardiovasc Thorac Surg. 2007;6:121-3.

24. Reyes A 2nd, Bove EL, Mosca RS, Kulik TJ, Ludomirsky A. Tricuspid valve repair in children with hypoplastic left heart syndrome during staged surgical reconstruction. Circulation. 1997;96. II-341-5. 


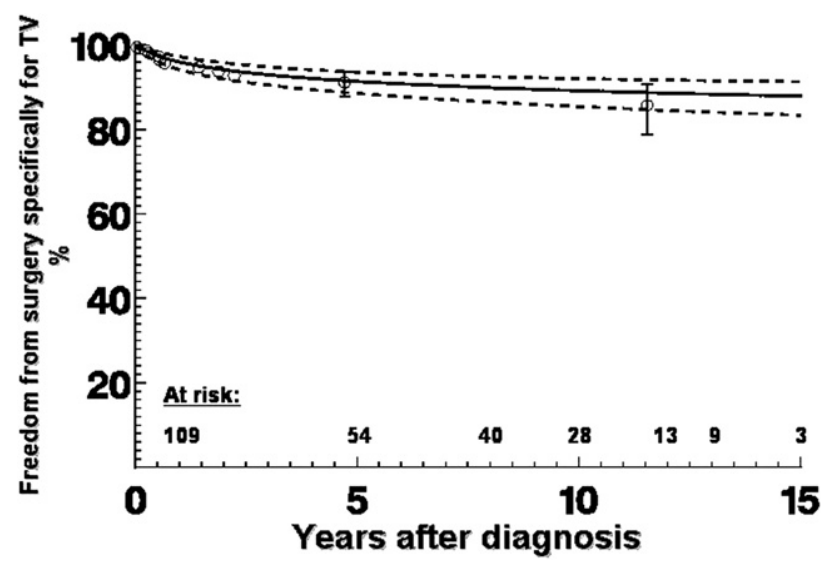

FIGURE E1. Freedom from TV intervention outside the staged univentricular sequence of operations (Norwood, partial cavopulmonary shunt, total cavopulmonary shunt). TV intervention as the primary operative procedure was undertaken in 11 children. Ten years after diagnosis, $89 \% \pm$ $2 \%$ children remained free from TV intervention as the primary indication for surgery. Circles represent nonparametric estimates at events; solid lines represent parametric determinants of continuous point estimates; dashed lines and bars enclose $70 \%$ confidence intervals. TV, Tricuspid valve. 

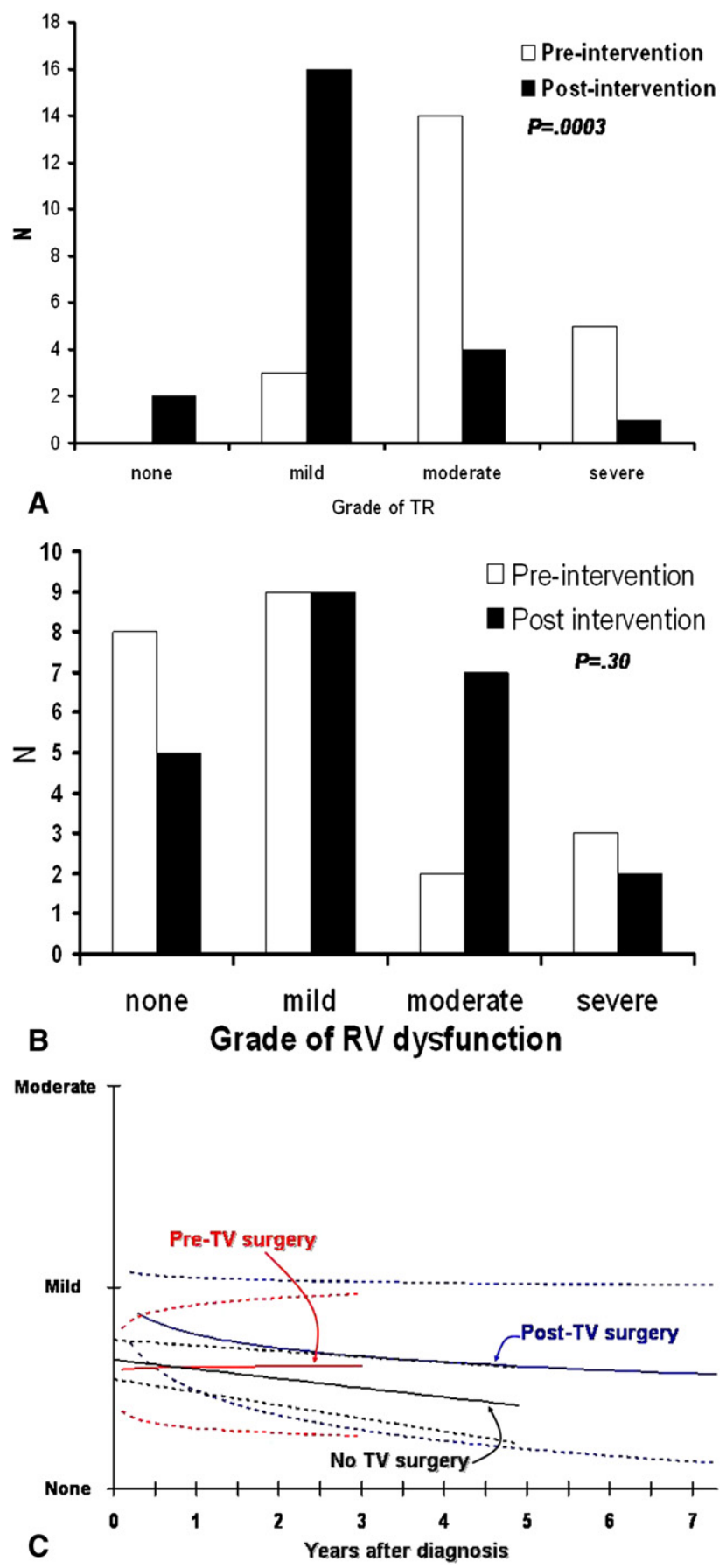

FIGURE E2. A, Histogram detailing the prevalence of echocardiographic grade of regurgitation immediately before and 24 hours after surgical repair $(\mathrm{N}=24)$. B. Histogram detailing the prevalence of echocardiographic grade of RV dysfunction before and 24 hours after surgical repair $(\mathrm{N}=24)$. C, Parametric regression estimates of the time-related change in echocardiographic grade of right ventricular dysfunction. The slightly higher incidence of postoperative right ventricular dysfunction after tricuspid surgery rapidly improved. Thereafter, right mean right ventricular performance for the cohort remained stable throughout follow-up, with no significant decline. Time has been entered as the log-transformation to improve model fit. Number of nonmissing values for analysis: patients

not receiving TV intervention, $\mathrm{N}=1796$; preoperative $\mathrm{TV}$ intervention, $\mathrm{N}=201$; postoperative $\mathrm{TV}$ intervention, $\mathrm{N}=193 . T V$, Tricuspid valve; $\mathrm{RV}$, right ventricular. 
TABLE E1. Patient demographics, baseline morphology, and Norwood features

\begin{tabular}{|c|c|c|c|c|c|c|c|}
\hline \multirow[b]{2}{*}{ Variable } & \multicolumn{3}{|c|}{ No TV intervention $N=195$} & \multicolumn{3}{|c|}{ TV intervention $N=24$} & \multirow[b]{2}{*}{$\begin{array}{c}P \\
\text { value }\end{array}$} \\
\hline & $\begin{array}{c}\text { Missing } \\
\text { values }\end{array}$ & Value & $\begin{array}{l}\% \text { or } \\
\text { range }\end{array}$ & $\begin{array}{c}\text { Missing } \\
\text { values }\end{array}$ & Value & $\begin{array}{l}\% \text { or } \\
\text { range }\end{array}$ & \\
\hline Death at any stage & 0 & 100 & 51 & 0 & 5 & 21 & .0049 \\
\hline Death without TV intervention & 0 & 95 & 49 & 0 & 0 & 0 & - \\
\hline TV repair & 0 & 0 & 0 & 0 & 24 & 100 & - \\
\hline Second TV repair & 0 & 0 & 0 & 0 & 3 & 13 & - \\
\hline Second TV replacement & 0 & 0 & 0 & 0 & 3 & 13 & - \\
\hline Birth weight $(\mathrm{kg})$ & 69 & 3.3 & $1.4-4.4$ & 7 & 3.7 & $2.5-4.5$ & .004 \\
\hline Male & 0 & 130 & 67 & 0 & 16 & 67 & $>.99$ \\
\hline Aortic atresia & 0 & 83 & 43 & 1 & 14 & 61 & .13 \\
\hline Aortic stenosis & 0 & 112 & 57 & 1 & 10 & 44 & .42 \\
\hline Shone syndrome & 5 & 9 & 5 & 1 & 0 & 0 & 60 \\
\hline Subvalvar stenosis & 92 & 15 & 15 & 9 & 1 & 7 & 69 \\
\hline Atrial septal defect & 34 & 150 & 93 & 3 & 20 & 95 & $>.99$ \\
\hline Ventricular septal defect & 92 & 58 & 56 & 13 & 4 & 36 & .11 \\
\hline Ventricular septal defect, moderate or large & 138 & 19 & 33 & 15 & 1 & 11 & .26 \\
\hline Atrioventricular septal defect & 5 & 22 & 12 & 1 & 1 & 4 & .48 \\
\hline Left superior vena cava & 113 & 22 & 27 & 10 & 2 & 14 & .51 \\
\hline Double-outlet right ventricle & 5 & 13 & 7 & 1 & 2 & 9 & .67 \\
\hline Anomalous pulmonary venous drainage & 5 & 9 & 5 & 1 & 1 & 4 & $>.99$ \\
\hline Right aortic arch & 119 & 4 & 5 & 9 & 0 & 0 & $>.99$ \\
\hline Anomalous coronary arteries & 118 & 4 & 5 & 9 & 0 & 0 & $>.99$ \\
\hline Coarctation & 81 & 99 & 87 & 8 & 8 & 50 & .001 \\
\hline Transverse aortic arch diameter (mm) & 65 & 4 & $3-5.5$ & 12 & 3.7 & $2-7.5$ & .72 \\
\hline Aortic annular $z$ score & 17 & -18 & -30 to +0.3 & 3 & -12 & -19 to -4 & .10 \\
\hline Grade of LV hypoplasia & & & & & & & .89 \\
\hline None & 0 & 1 & 0.5 & 0 & 0 & 0 & - \\
\hline Mild & 0 & 4 & 2 & 0 & 0 & 0 & - \\
\hline Moderate & 0 & 8 & 4 & 0 & 1 & 4 & - \\
\hline Severe & 0 & 182 & 93 & 0 & 23 & 96 & - \\
\hline \multicolumn{8}{|l|}{ Grade of LV dysfunction (patent aortic valve only) } \\
\hline Endocardial fibroelastosis & 5 & 19 & 10 & 5 & 4 & 21 & .29 \\
\hline Mitral atresia & 5 & 47 & 25 & 1 & 11 & 48 & .03 \\
\hline Mitral stenosis & 5 & 39 & 21 & 1 & 4 & 17 & $>.99$ \\
\hline Parachute mitral valve & 4 & 11 & 6 & 1 & 0 & 0 & .61 \\
\hline Mitral annular $z$ score & 50 & -10.9 & -20 to -0.8 & 8 & -11 & -14 to -6 & .01 \\
\hline Grade of RV dysfunction & & & & & & & .95 \\
\hline None & 0 & 156 & $80 \%$ & 0 & 20 & $83 \%$ & - \\
\hline Mild & 0 & 27 & $14 \%$ & 0 & 3 & $13 \%$ & - \\
\hline Moderate & 0 & 10 & $5 \%$ & 0 & 1 & $4 \%$ & - \\
\hline Severe & 0 & 2 & $1 \%$ & 0 & 0 & $0 \%$ & - \\
\hline RVOT stenosis & 1 & 0 & $0 \%$ & 11 & 0 & $0 \%$ & - \\
\hline Minimum branch pulmonary artery $z$ score & 41 & -0.36 & -29 to +3.0 & 6 & -1.4 & -4.4 to +0.6 & \\
\hline Grade of TV regurgitation & & & & & & & .35 \\
\hline None & 0 & 34 & $17 \%$ & 0 & 7 & $29 \%$ & - \\
\hline Trivial & 0 & 80 & $41 \%$ & 0 & 12 & $50 \%$ & - \\
\hline Mild & 0 & 67 & $34 \%$ & 0 & 4 & $17 \%$ & - \\
\hline Moderate & 0 & 12 & $6 \%$ & 0 & 1 & $4 \%$ & - \\
\hline Severe & 0 & 2 & $1 \%$ & 0 & 0 & $0 \%$ & - \\
\hline TV stenosis & 49 & 0 & $0 \%$ & 6 & 0 & $0 \%$ & - \\
\hline Tricuspid annular $z$ score & 55 & -0.54 & -10 to +6 & 14 & -1.3 & -5.2 to +2.4 & .41 \\
\hline Median age at time of Norwood (d) & 0 & 6 & $0-175$ & 0 & 5 & $2-33$ & .28 \\
\hline Median weight at time of Norwood (kg) & 0 & 3.3 & $1.4-19$ & 0 & 3.6 & $2.2-5.2$ & .94 \\
\hline \multicolumn{8}{|l|}{ Type of Norwood operation } \\
\hline Classic & 34 & 131 & $81 \%$ & 3 & 20 & $95 \%$ & .13 \\
\hline
\end{tabular}




\begin{tabular}{|c|c|c|c|c|c|c|c|}
\hline \multirow[b]{2}{*}{ Variable } & \multicolumn{3}{|c|}{ No TV intervention $N=195$} & \multicolumn{3}{|c|}{ TV intervention $\mathrm{N}=\mathbf{2 4}$} & \multirow[b]{2}{*}{$\begin{array}{c}P \\
\text { value }\end{array}$} \\
\hline & $\begin{array}{c}\text { Missing } \\
\text { values }\end{array}$ & Value & $\begin{array}{l}\% \text { or } \\
\text { range }\end{array}$ & $\begin{array}{c}\text { Missing } \\
\text { values }\end{array}$ & Value & $\begin{array}{l}\% \text { or } \\
\text { range }\end{array}$ & \\
\hline Brawn modification & 34 & 26 & $16 \%$ & 3 & 1 & $5 \%$ & .32 \\
\hline Modified BT shunt & 22 & 153 & $88 \%$ & 1 & 21 & $91 \%$ & $>.99$ \\
\hline Sano RV-PA shunt & 22 & 20 & $12 \%$ & 1 & 2 & $9 \%$ & $>.99$ \\
\hline Median shunt diameter (mm) & 43 & 3.5 & $2-5$ & 3 & 3.5 & $3-4$ & .67 \\
\hline Total cardiopulmonary bypass duration (min) & 31 & 121 & $48-437$ & 3 & 122 & $99-165$ & .62 \\
\hline Total myocardial ischemic duration (min) & 32 & 51 & $19-127$ & 3 & 62 & $20-117$ & .03 \\
\hline Total circulatory arrest duration (min) & 50 & 43 & $0-100$ & 3 & 14 & $1-70$ & $<.001$ \\
\hline Minimum core temperature $\left({ }^{\circ} \mathrm{C}\right)$ & 87 & 17 & $14-23$ & 19 & 16 & $15-22$ & .82 \\
\hline Systemic oxygen saturations at end of procedure $(\%)$ & 134 & 73 & $50-87$ & 20 & 76 & $65-80$ & .76 \\
\hline Delayed sternal closure & 46 & 92 & $62 \%$ & 4 & 16 & $80 \%$ & .14 \\
\hline
\end{tabular}

$B T$, Blalock-Taussig; $L V$, left ventricle; $P A$, pulmonary artery; $R V O T$, right ventricular outflow tract. Frequencies are expressed as the proportion of nonmissing values. 